HÁRY, András

\title{
FUTURE POSSIBILITIES, SOCIAL CHALLENGES AND ADAPTATION REQUIREMENTS OF INDUSTRIAL PROGRESS
}

The paper addresses the technological change that is currently happening in industry. First, a review of the global trends that impact industrial developmentsis made, then a summary ofexpanding intelligent technologies and their systems. The report describes in detail the concept of Industry 4.0 and its major technology-related aspects. At the end of the paper, a summary of social consequences is addressed, especially concerning generational concerns connected to the current change in industrial technology. The purpose of the study is to raise some special aspects and considerations in the given subject.

\section{Key words: Industry 4.0, intelligent, technology change}

In recent decades technological development has accelerated and created many challenges to businesses and to individuals alike. This article addresses basic questions and dilemmas regarding management and the broader social environment. It touches on issues that can be useful for all business ventures that would like to take advantage of the products of current technological advancement, or who would simply like to remain competitive on the market amidst today's rapid changes. The purpose of the study is to raise some special aspects and suggest certain considerations related to the already running industrial revolutions.

\section{Worldwide Megatrends}

Recognizing the trends and tendencies that shape our future is the first step towards intelligent diversification and conscious action. Megatrends are all the changes and tendencies that have fundamental, long-term impact on a global scale. Understanding the characteristics of large-scale trends, and adaptation to the new conditions that possibilities bring, can not happen unless one forms and uses a network approach. Megatrends shape resources on which a region, a company cluster, or a technological development platform can base their profiles. Trying to unpack the nature and implications of such megatrends, one comes across basic principles or laws that companies can rely on in developing their business.
There are several megatrends in the world today; I would like to highlight a few of these, which are directly relevant for company management:

- demographic changes,

- disruptive technologies (available for the masses),

- mobility,

- volatility,

- increasing polarisation,

- ability to adapt to changes,

- generational gap.

Technological changes are partly the source, partly the consequence of the above-mentioned global megatrends, in line with consequences of an overview in this subject (http://www3.weforum.org/docs/WEF_Future_of_Jobs.pdf).

\section{What are the characteristics of intelligent technologies?}

Typically, there are two types of technological innovation. One is a paradigm change, the other employ sold methods in a novel form. The first category comprises technologies whose approach is fundamentally different from those of earlier ones, and usually brings about new ways of production based on fresh, new research results and ideas (e.g. information technology, 
nanotechnology). The second category - more common than the first - comprises technological innovation that combines already existing elements resulting in a novel system or solution. An example of this phenomenon is the intelligent environment where connecting different appliances (alarm, heating and electrical system, electronical devices, kitchen appliances) into one network creates a new valuable product for consumers (Nagy-Kulcsár, 2006). If companies are to stay competitive on the market, such systematic innovations will certainly have to be the way forward. This dual phenomenon, i.e. paradigm change versus developing already known methods, is also called ,the innovator's dilemma" (Christensen, 1997).

\section{Contemporary Technological Systems}

The revolution of digital technology „took over” chains of production and transport years ago. Today companies focus more on creating intelligent systems of production and distribution, and try to become more competitive using available production and logistical data. There are many examples that show what has changed in recent years regarding the handling of information and creating network-based solutions. For instance, we now have Big Data, IoT (Internet of Things) and IoS (Internet of Services). There is a boom in advanced mobile communication devices, robots, automotive vehicles and transportation devices. Also, companies use more and more alternative energy sources to run industrial plants. Such new technologies can help to reduce costs while increasing the pace of production flows, and the reliability and controllability of production processes. Thus, companies, both manufacturers and logistical service providers, that started implementing new technologies into their business models are on the right path to becoming more and more competitive on the market.

\section{Challenges of the Abundance of Data and Information}

Increasing digitalisation of information in operational processes (Big Data), coupled with state-of-the-art analytical methods and the construction of effective process models are transforming models of management as well. Company leaders usually see that implementing such technologies will only be useful if, in the long run, they will be integrated into the structures of management as well. This integration, however will require profound systematic changes. Furthermore, it will also require the renewal of professional training of employees because data-based decision-making is a skill that needs to be learned. The greatest obstacle to such development is that company leaders are not yet certain whether the organisational units that collect and process data are the ones that can make consistent improvements in the reliability ofsupply chains. Therefore, experts suggest that when they want to make such improvements, companies should work with traditional methods of measurement and analysis, upon which they should build „breaks” into the system. If this convinces leaders that data-based operations indeed support decision-making measures, and the first results make this visible, then they may become more confident to use evidence-based methods. Having adequate information and data, transport routes could become shorter, which would cut costs, save time and increase productivity. Analysing available data correctly is not only important for developing production or its logistical systems. It is also crucial to uncovering and correcting weak elements of the entire supply chain, for example transport costs and time.

\section{Networks Everywhere}

One of the intelligent technologies is the so-called IoT (Internet of Things). It refers to physical objects or equipment - such as machines producing or hauling goods, or spare parts - to which sensors or any other type of data-communication devices are added. Tools with such built-in sensors or data-communicative functions can monitor, coordinate and control through the internet. This enables communication between machines (M2M, Machine-to-Machine). As a result, networks can be built where devices can communicate and exchange information while simultaneously they collect and analyse data about it. In this way Big Data and IoT go hand-in-hand. Today it is becoming more and more natural to control our TV from our mobile phones and TVs are more like home-information centers. Increasingly equipment can connect to the wi-fi network as well. It is interesting to think about what kind of networks can be created and what degree of intelligence we can achieve in a factory or warehouse where we use robots, and automatised transport routes, storing devices and forklifts and where the work is continuously supported by combined systems of energy-supply, storage control and transport optimalisation. Through these integrated systems companies can make unprecedented progress in efficiency, predictability and realtime controllability.

\section{Industry 4.0: Companies of the Future}

Generally we speak about industrial revolution when some technological innovation produces a drastic growth in the efficiency of productionsystems, in other words, these systems undergo a paradigm change. 
- The first industrial revolution started in the second half of the 18th centrury when the steam engine brought about systematic industrial production.

- The second industrial revolution spanned from the second half of the 19th century to the end of the First World War and resulted in mass and serial production; its peak was Ford's Model-T.

- The third industrial revolution is sometimes called the ,digital revolution”. It started in the second half of the 20th century and has brought about the global-wide use of logical circuits, the spread of computers, mobile phones and the internet. Concurrently, the first steps towards the automatisation of production were taken.

- The fourth industrial revolution is usually referred to as „Industry 4.0” by mostly German experts. It is a process that is already happening but will reach its peak in the near future when it creates „smart manufacturing”, i.e. the rethinking of production technologies with a network-based approach, and new business models that take advantage of this approach. (Figure 1)

During the first industrial revolution the appearance of mechanical-based production chains jump started all the great radical changes that were later given a further boost by the spread of electricity during the second industrial revolution. During the third industrial revolution, automatisation offered new alternatives for

\section{Complexity of Industrial revolutions and Production Systems}

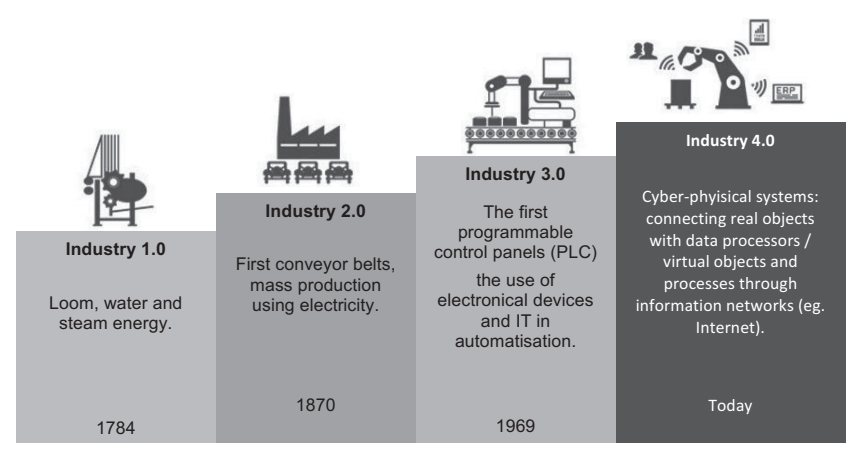

(Source: Heng, 2014)

human labour and made the processes of production faster and more specialized. Today it is primarily the intergation of these elements that will produce a breakthrough, because we will be able to use technologies and approaches that will make it possible to operate and control more complex systems and entire suply chains simultaneously. This level of development will require both the seamless integration of systems of production and their IT support systems, i.e. their treatment as $c y$ ber-physical systems, and the adoption of a radically innovative management approach.

\section{Industry 4.0 ecosystem}

Figure 2

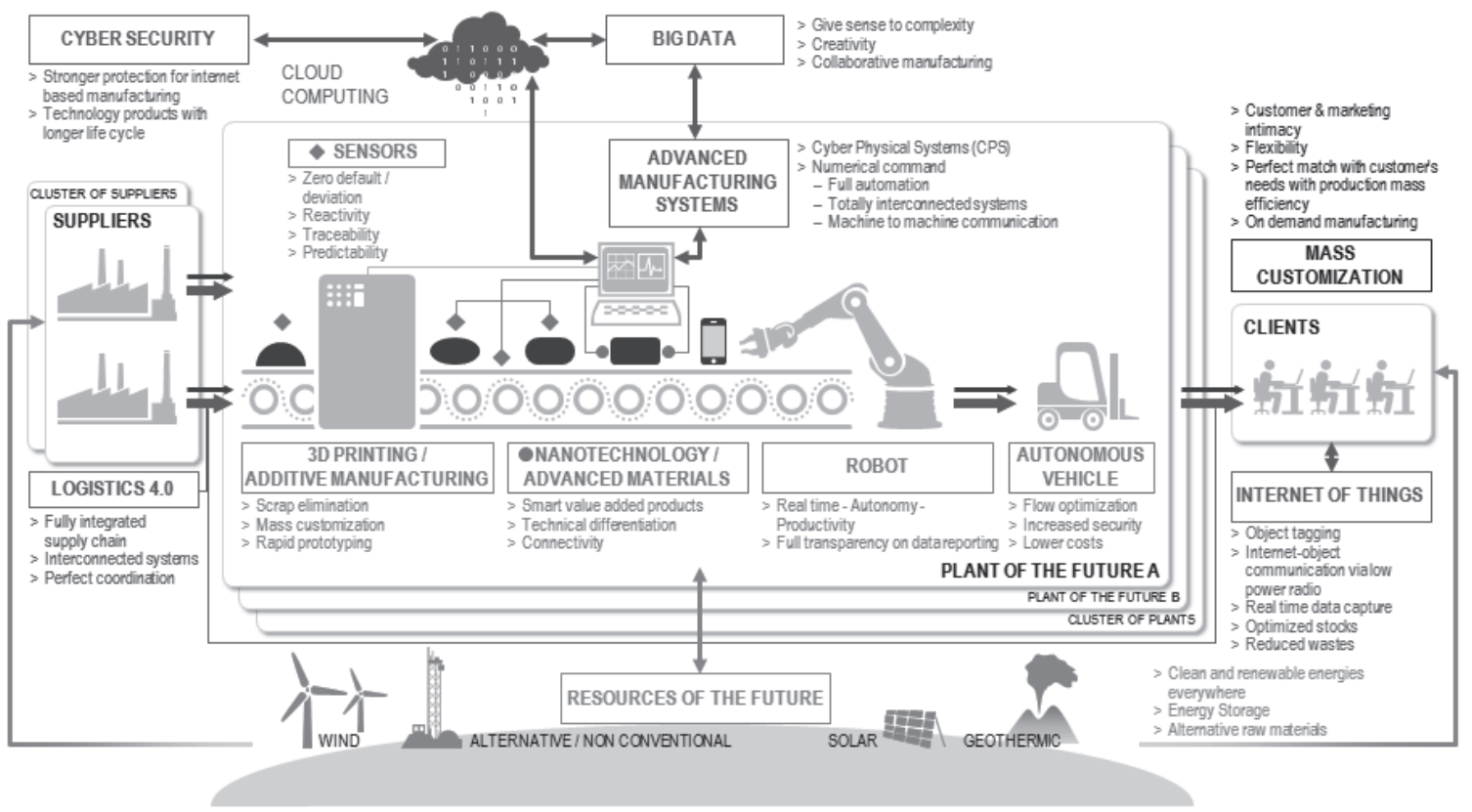

(Source: Morris - Berger, 2015) 
Hermann (2015) collected six principles for design regarding Industry 4.0:

- Ability to cooperate: the ability to harmonise cyber-physical networks (e.g. product carriers, assembly stations and endproducts), and enabling communication among people, SmartFactories, through the Internet of Things.

- Virtualisation: creating a virtual copy of the SmartFactory, on the basis of information derived by sensors (monitoring physical processes), virtual factory models and simulation models.

- Decentralisation: the decision-making ability of cyber-physical systems within the Smart Factory.

- Real-time capability: the ability to collect and process data in real time.

- Service-centered approach: providing services (for cyber-physical systems, people or for the SmartFactory) through the Internet of Services.

- Being Modular: the ability of SmartFactories to adapt to changing circumstances by changing or expanding certain elements.

The basis of Indsutry 4.0 is that we create smart units that are autonomous but that are in close connection with one another and are intelligent. These complex systems can optimise through detailed inter-connected models in order to fulfil pre-set goals. Besides arranging these smart elements into systematic networks, this process also requires their fine-tuning in „cyber spa$c e$ ". We can do this through a model-based optimalisation and a new type of development of simulation devices. Accordingly, Cyber-Phsyical Production Sytems (CPPS) will create intelligent networks comprising not

\section{The logic of cyber-physical systems bringing about Industry 4.0}

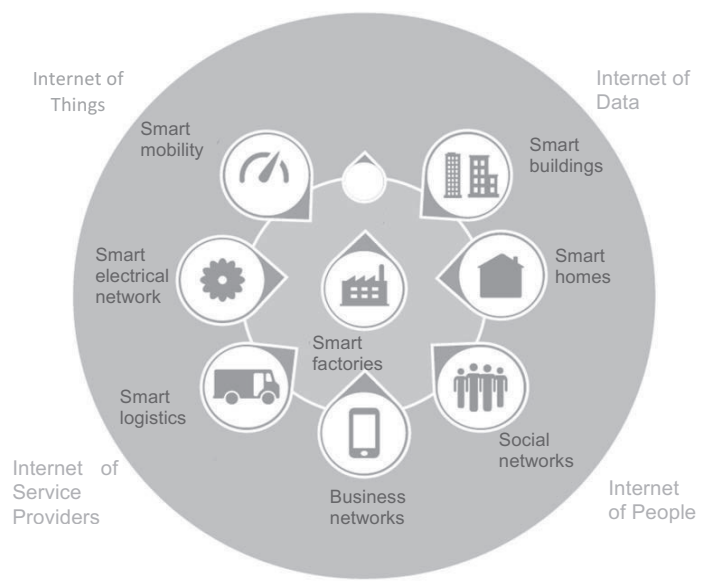

(Source: Deloitte, 2014) only classic production tools but also entire supply chains including energy systems, logistical processes, systems of building management and so on. (Figure 3)

A comprehensive study (TÁMOP 2015) has shown that restructuring production systems in this way can only happen step-by-step, through a digital upgrade of current equipment. There will not be any need to build new factories, but we can gradually make current factories more up-to-date by modernising individual elements and connecting them to a wireless network. We can thus ensure the constant flow of information and can process signals from different sensors. It will then be possible to recognise complex outcomes, foresee and analyse problems, and correct further steps based on the results. Thanks to the increasing number of data collecting stations in the world today, there are enormous amounts of data available. While humans can not handle this boom of data, they are easily processed by machines. Thus, it seems logical that in certain areas of production machines communicate with machines making a vast array of processes more efficient, flexible and cost-effective. Sensors placed in different parts of machines can chart the surrounding environment and track their wireless communication.

These networks differ from current mechatronic systems in that they are able to communicate and cooperate with their environment and by learning new behavioural patterns and strategies, they can adjust their behavior accordly. This makes production more economical, even when it comes to different types or small numbers of products. With the help of such built-in sensors, machine-to-machine communication and active semantic product memory, it is possible to optimise resources as well as make complex production processes more environmetally friendly and financially more efficient. Machines that can understand their context will fundamentally change industrial production.

All of this requires highly effective communication: the intelligent processing of all contextual information. Softwares play a central role in this because it is not enough to collect and continuously forward information but also necessary to decode it. The software of our Future Factory, thus, needs to have a conceptual system, which allows us to describe the function of production units, tasks, stages and results. Industry 4.0 uses the internet for machine-to-machine communication which is why such systems are called the Internet of Things. This enables Industry 4.0 to acheive the highest degree of complexity, reliability and stability. With the help of cyber-physical systems a factory can be transformed while it is running. Sensors can be integrated as necessary and different pieces of equipment can be run independently if needed. 
Connecting these different components into one system will revolutionise Industry 4.0. Of course, a common protocoll and built-in interfaces are necessary as everything happens in real time. Besides electronic integration though, the issue of data security is also rather important and it is a problem that many companies will need to face and solve in the near future. Currently, we witness the continuous process of connecting components and creating networks that are already producing measurable results for companies. The installment time for machines is reduced because units that are produced simultanously have a much lower demand for cables and wiring. Furthermore, users can ensure more stability in their productivity through constant monitoring and they can ensure the security of production processes through steady data analysis (Shaw, 1990).

\section{Technological Foundations of Industry 4.0}

In what follows a few elements will be highlighted that are especially important for Industry 4.0, as also discussed Abonyi-Miszlivetz in their study from 2015.

\section{Virtual Design}

The end-to-end virtual design is one of the corner stones of Industry 4.0 and has brought a new era in production. In the centre is data itself: how it is processed, how it is distributed among devices and how it is transformed into a virtual prototype and finally, an endproduct. Utilising virtual methods in engineering has several advantages: for instance using the entire digital ,script" of a product, the data can move through standardised interfaces from the engineer to the production line. The digital script can also make installing, running and maintenance more efficient. Virtual prototypes, together with the digital script of all of their components have immense possibilities both in customised production and in experimentation with new technologies. Based on this concept it is possible to make just one piece of a unique product on the same production line.

\section{IT Support and Networks}

IT infrastructure will also expand in time - more and more intelligent devices will be incoporated into each machine and system. The connection and the data flow among these machines and devices will occur amidst various environmental conditions, thus it is vital that the smallest compartment is built into the data security system. Security requirements of compartments for network devices are also strict.

Traditionally consistency is seens as the greatest asset in production. It is considered as important as data security. Industry 4.0 is changing this traditional view, making security the no. 1 priority. Built-in interconnected sensors contribute to the goals of Industry 4.0 in a unique way: costs are reduced, production becomes more rationalised and long-term competitiveness is targeted. Soon several new functions and features will become possible such as customs production; making quick changes in the configuration; or the unprecedented control of resources, production time and consumption. But a production device that is part of a network needs to be monitored constantly, not only because of environmental factors (temperature, humidity etc.) but also because of unauthorised access.

\section{Machine-Machine Communication, Integrated Production Management}

Running machines and complex networks will be strengthened by M2M (Machine-to-Machine) technology in many respects. M2M is itself a new paradigm, which enables the remote control of machines and their supervision. It helps to create efficient

- remote supervision,

- remote diagnostics,

- computerised remote advisory services.

On request it is possible for the centre to get real-time information about the condition of remote machines, and receive statistics of their productivity. Two-way communication enables even some program modifications in their micro-controlled networks. The later needs to be carried out while observing strict info-communication regulations. One of the basic conditions of M2M technology is for the machines to have the ability to communicate. For this they require a unit, a modem or some other communication gateway, which can create a connection between the machine's own controlling network and the greater network.

Regarding data communication of mobile machines, it is most popular to use the technology of mobile phones.

Today, up-to-date production processes and devices are equipped with the ability tolearn and knowpartly through traditional algorythms and databases built into their brains, partly through new methods offered by AI (expert systems, intelligent control, learning neural networks).

In sum, built-in artificial intelligence makes Intelligent Manufacturing Systems (IMS) and production without human supervision a reality. Intelligent manufacturing encompasses several subdivisions (computer-numeric control, computer-aided design and manufacturing technologies, robotics, transport of materials, production IT, organisation and supervision, production programming, waste analysis, etc.). 
The Impact of Industry 4.0 on Business Models

One of the most important characteristics of the features and mechanisms mentioned above is how integrated these different functions are during a life cycle. Integration will bring about a shortened span of innovation time and production processes and consequently will result in lower unit prices and potentially, enhanced competitiveness. (Figure 4)

\section{Advantages of Integration and Cooperation}

Figure 4

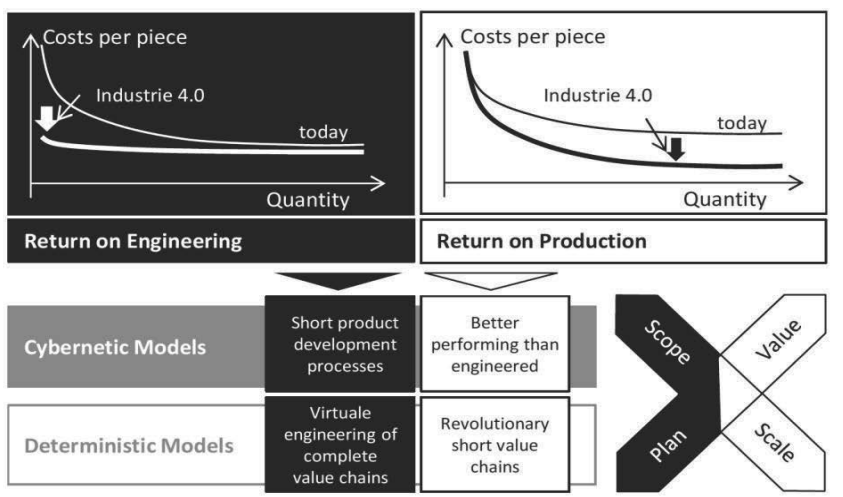

(Source: Schuh, 2014)

Innovation time can be significantly reduced by tools and methods designed for quick prototype design. Such processes of development are usually assessed based on the time that has elapsed between product idea and the start of manufacturing. Simulation devices can help to directly reduce problems that occur during production. They can also help to estimate productivity and identify possibilities for improvement. Simulation devices help us develop processes and products together, in a synchronised manner. A key indicator of this aproach is the preparation and evaluation time of simulation tests, which is signifi-

\section{Evolution of productivity}

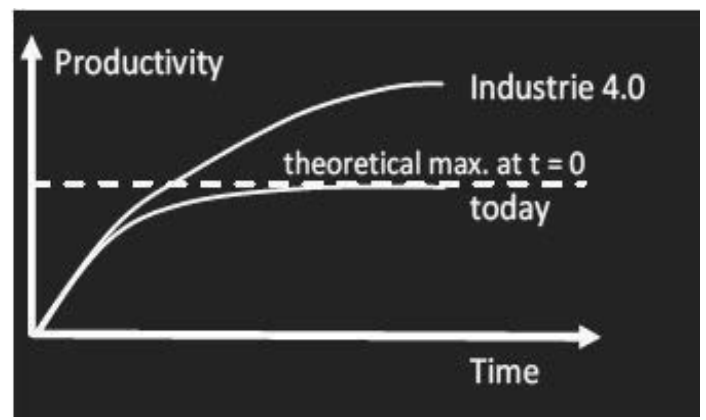

(Source: Schuh, 2014) cantly shorter than in the case of more traditional technologies (Schuh, 2014). (Figure5)

Besides quantitative and economic considerations, the most important success factor is the capacity for customs manufacturing. Production units usually complete distinct, specialised tasks, so different functions are done by different machines. Because of this degree of specialisation, manufacturing systems are becoming increasingly complex. In the near future, problems that stem from such complexity will need to be solved by merging several functions. For instance, robots will need to be able to tackle more tasks simultaneously. The merging of disparate functions will result in shortened production time, which will allow for a more balanced production process. Production units will be utilised more evenly (Schuh, 2014). In view of such expectations, Industry 4.0 is in sharp contrast with earlier trends of Taylorist development that emphasized more specialized production tools. The goals is of course not to go backwards, but to find the adequate number of work stations, workers and necessary functions. The decentralised running of independent manufacturing and assembling units can only be done through their strong interconnection and cooperation. Designing processes of cooperation can also be done in the ,virtual factory" and its simulation devices.

\section{Social and Demographic Implications}

The impact of Industry 4.0 and intelligent technologies on the current job market is an important issue. In order to produce an assessment, it is necessary to review the current trends with a main focus here on demography-related aspects. (Further conclusions can be found in the following study: Meeting 21st-Century Challenges with Science, Technology and Innovation a Roadmap for Policymaking). Wider view than demography can be the subject of a further analysis, beyond the scope of the current discussion.

As the population of developing countries increases, the population in developed countries is decreasing. The population of Europe has been declining year after year, and most significantly in Eastern Europe. Additionally, the problem of ageing societies must be faced, especially in the EU countries. (Figure 6)

Such demographic tendencies suggest that new technologies, i.e. Industry 4.0 and intelligent technologies, that are able to increase production rates despite declining populations are becoming increasingly important.

Finally, another important factor is the generational implications. Research shows that generation Y (19801995) has socialized in consumerism; their lifestyle and their relationship to technology is in sharp contrast to that of their parents (Tari, 2010 and Tari, 2011). This ge- 
neration is free, ambitious, the product of internet and virtual communication. They are open-minded, pragmatic and inclusive. Growing up they have received much validation from their parents, they are reluctant to be adults, and they delay life events and life phases: they finish school later, they start working later, they start families later. They are self-conscious employees who change jobs without much emotional turmoil. At work they do not follow their parents' example: they want to shape their place of work according to their needs. They strive for a work-life balance and do not want to become enslaved to their work. Many refer to this generation as „children of the digital age” or ,, internet generation".

\section{Demographical changes in Europe and Ageing} in Hungary

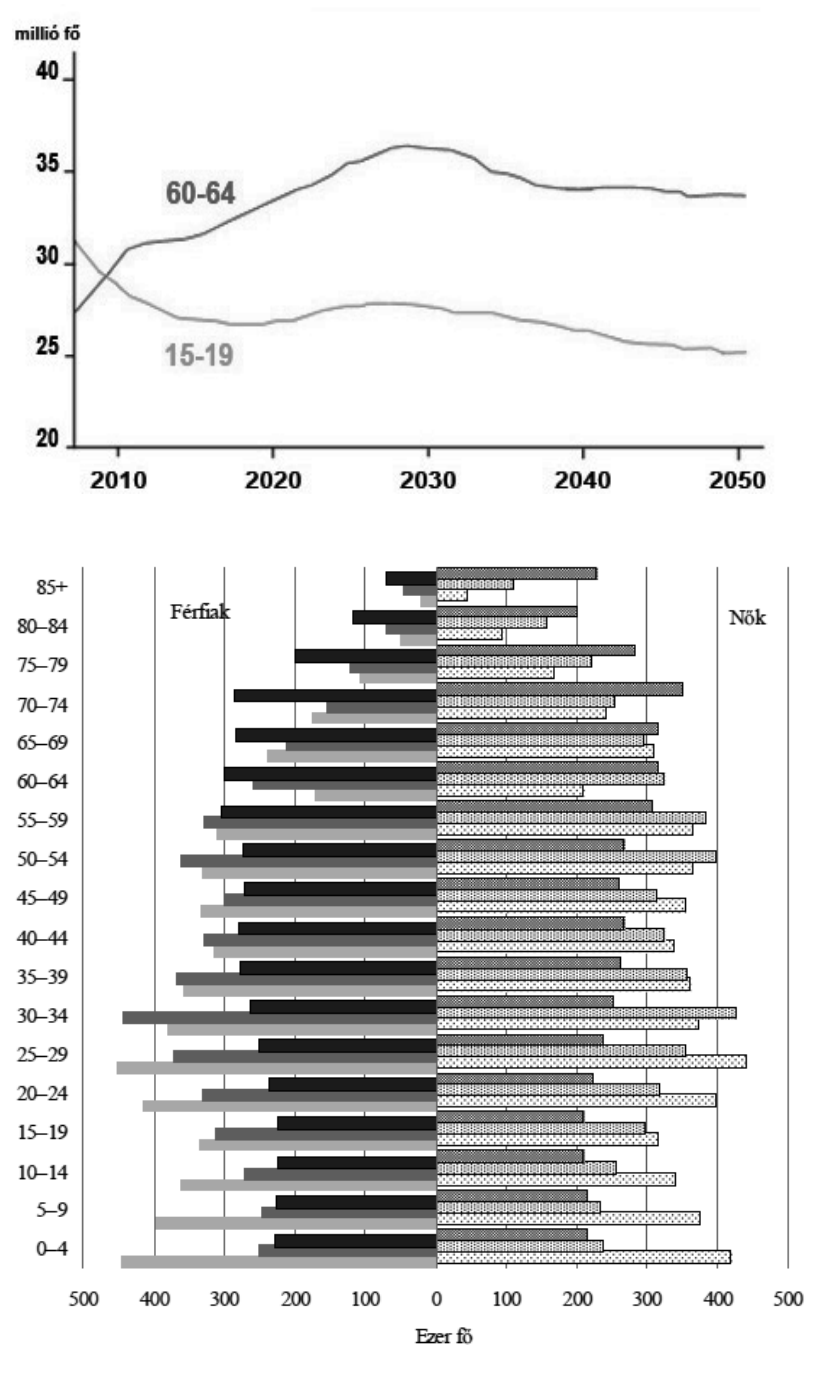

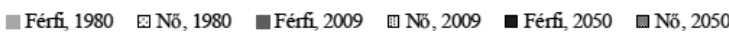

(Source: Schuh, 2014)
Others argue that the so-called generation $\mathrm{Z}$ (those born after 1995) has an even higher inclination to be skilled at information technologies and are even more flexible and literate in the use of new electronic gadgets. For generation $\mathrm{Z}$ everything is available through the internet.

The profound technological changes, referred to as Industry 4.0, has profoundly shaped these generations. This is the reality in which they can be truly efficient and productive.

\section{Conclusions}

Understanding the current trends and tendencies that shape our future is the first step towards intelligent adaptation and conscious action. It is not possible to stop the unfolding of these global processes, but their deeper understanding is vital to ensuring continuous development and competitiveness at the level of a region, a company, or the individual.

Currently there are two processes that are in the foreground (as key conclusions of this paper): first, the formation of intelligent manufacturing and distribution systems; second, companies are working to transform data derived from production and logistical processes to their competitive advantage. New technologies make it possible to reduce costs and at the same time increase the flow of products and the reliability and controllability of production processes.

Today, the most advanced global systems are those that can work with innovative methods of management and can sustain a strong integration of manufacturing systems and their IT support systems, treating both as one cyber-physical network. The basis of Industry 4.0 is the formation of autonomous, smart units that are closely connected to one another. Their complex systems are run by complex, detailed models.

Similarly to other technological changes, Industry 4.0 is not an easy transformation. It needs stable strategies, clear concepts for development, committed workers and an open-minded business environment where new technologies can be tested and used. If these conditions are met, then a factory or a service-provider have fairly good chances to become more competitive and develop further.

\section{References}

Abonyi, J. - Miszlivetz, F. (2015): Hálózatok metszéspontjain - A negyedik ipari forradalom társadalmi kihívásai. Kőszeg-Szombathely: Savaria University Press, 2016

Christensen, C. M. (1997): The Innovator's Dilemma. Cambridge, Mass.: Harvard Business School Press 
Deloitte (2014): Challenges and solutions for the digital transformation and use of exponential technologies. Deloitte.

Heng, S. (2014): Industry 4.0 Upgrading of Germany's industrial capabilities on the horizon. Frankfurt: Deutsche Bank Research

Hermann, P. O. (2015): Design Principles for Industrie 4.0 Scenarios. Dortmund: Technische Universität Dortmund

Hosseini, M. (2015): What will the future look like under Industry 4.0 and digital transformation in the healthcare space? Stuttgart: Roland Berger (http:// www.medteceurope.com/sites/default/files/6.morris_hosseini_-_presentation_to_share_0.pdf)

Nagy-Kulcsar, L. - Dobra, P. - Moga, D. - Dumitrien, M. - Stroia, N. (2006): Opportunities of Emerging Technologies for Smart Houses - City-wide Energy, Gas and Water Measurement Networks. Cluj Napoca
Shaw, M. (1990): Prospect for an Engineering Discipline of Software. Technical Report of the Carnegie Mellon University, CMU/SEI-90-TR-20.

Schuh, G. - Potente, T. - Wesch-Potente, C. - Weber, A. R. - Prote, J.-P. (2014). Collaboration Mechanisms to Increase Productivity in the Context of Industrie 4.0. Procedia CIRP, 19 (RoMaC), 51-56. http://doi. org/10.1016/j.procir.2014.05.016

TÁMOP (2015): TÁMOP 4.2.1.D-15/1/KONV-20150007 project analytical study

Tari A. (2010): Y generáció: klinikai pszichológiai jelenségek és társadalomlélektani összefüggések az információs korban. Budapest: Jaffa Press

Tari A. (2011): Z generáció: klinikai pszichológiai jelenségek és társadalomlélektani szempontok az információs korban. Budapest: Tericum Press

Global Challenge Insight Report: The Future of Jobs http://www3.weforum.org/docs/WEF_Future_of_Jobs. pdf 